\title{
Insulation systems for structures on pile supports
}

\author{
Vyacheslav Semenov ${ }^{1 *}$, Igor Bessonov ${ }^{2}$, Ekaterina Zinovieva ${ }^{1}$ and Elizaveta Mednikova ${ }^{1,3}$ \\ ${ }^{1}$ Moscow State University of Civil Engineering, Yaroslavskoe shosse, 26, Moscow, 129337, Russia \\ ${ }^{2}$ Scientific Research Institute of Building Physics of the Russian Academy architecture and \\ construction sciences, Lokomotivny proezd, 21, Moscow, 127238, Russia \\ ${ }^{3}$ Design and architectural bureau, Institute of Construction and Housing and Communal Services, \\ GASIS Academy of Continuing Professional Education, Higher School of Economics, Myasnitskaya \\ ulitsa, 20, Moscow, 101000, Russia
}

\begin{abstract}
Construction on problem soils or in permafrost conditions involves using of pile foundations with a ventilated space under the floor structure. In this case, additional thermal insulation is required under the first-floor structure (above the ventilated space). The aim of research was to develop insulation systems for buildings on pile foundations for different climatic zones, including conditions of the arctic region and other regions with a predominance of ever-frozen ground. With the help of the THERM computer program, the conditions of bidimensional heat interchange in the enclosing structures of a building with pile foundation were simulated. The resulting models were analysed in terms of the thermophysical characteristics of the structures. As a result, the optimal version of the insulation system was chosen, effective both in the climatic conditions of the midland and in the especially cold conditions of Yakutia and Trans-Polar region (The Subarctic). This system included insulation with mineral wool slabs along the facade walls, with extruded foamed polystyrene along the basement part and the floor structure, and with rolled foamed polyethylene (with the formation of a seamless insulation shell) along the ventilated space under the floor structure and above, on top of insulation boards.
\end{abstract}

\section{Introduction}

The minimum permissible heat transfer resistance of walls and coverings of buildings for various purposes and different climatic conditions is regulated by SP 50.13330-2012 and it is determined by the operating conditions of the insulation systems, including atmospheric manifestations [1-3]. During the reconstruction of walls and coverings, the thickness of the additional thermal insulation layer was determined based on the difference between the required and existing heat transfer resistances.

The effective use of thermal insulation is based on the following conditions. Firstly, the thermal insulation material is used only dry or at the equilibrium moisture content. Any excessive moistening of the structure leads to an increase in the thermal conductivity of the

* Corresponding author: science-isa@yandex.ru 
insulating layer and a sharp drop in the real thermal resistance. Secondly, the installation of insulation boards must be close to each other and to the structural element. The appearance of a gap between the boards is not allowed due to leading to the formation of thermal bridge, which will increase heat loss through the enclosing structure [4-6].

Moisture can enter building structures in various ways. The movement of the vapour-air mixture occurs constantly in the construction of the basement part of the wall and foundation. Moisture condensation is possible under certain conditions, for example, when the temperature in the material reaches the dew point. Capillary rise of ground moisture through the foundation structure and through the capillaries of the wall material can occur if the insulation system is incorrectly performed. All these reasons make it advisable to use seamless heat-vapor-waterproofing shells [7-9] in building insulation systems.

Construction in regions where negative temperatures prevail, strong winds and other atmospheric cataclysms are possible, should take into account the characteristics of these regions. Firstly, the insulating shell of the building should not only provide the standard thermal resistance along the surface of the wall, but also minimize possible heat loss through cold bridges and direct infiltration of cold air through the joints of structures. Only in these cases can we expect a satisfactory indoors climate and reduce heat loss.

Most regions beyond the Arctic Circle, as well as Yakutia and so on, are characterized by the presence of permafrost. Soils in a frozen state are quite capable of withstanding the load from buildings, but when thawed, they completely or partially lose their bearing capacity, which leads to deformations of foundations and structures or to the destruction of objects. The need to preserve soils in a frozen state and the fact of their presence are the second feature of construction in regions with a cold climate.

The problem of preserving permafrost in modern construction is solved in two ways. Abroad, the predominant solution is the use of floating foundations, arranged according to the type of "Swedish foundation". This includes the following layers: sand (or gravel-sand) preparation over the soil layer, waterproofing, thermal insulation boards laid in several layers with offset joints, and a reinforced concrete screed on which the supporting frame of the building rests. It is recommended to use extruded foamed polystyrene boards as thermal insulation. The thickness of the insulation is determined from the thermal engineering calculation according to the required standard thermal resistance.

These technologies are gradually (and not entirely successful) being introduced in Russia. However, pile-based construction is predominant in the Russian north. The technology assumes the creation of a ventilated space between the ground and the floor of the first floor with multilayer insulation under the floor [10,11]. It should be noted that, according to existing traditions, an insulating shell is used, consisting of rigid mineral wool boards and boards of extruded polystyrene foam, laid with displacement joints. The thickness of such an insulating cake can be up to $0.6 \mathrm{~m}$.

The aim of the study was to develop insulation systems for buildings on pile foundations for different climatic zones, including in the Arctic, as well as other regions with a predominance of permafrost.

\section{Materials and Methods}

The realization of the research goal involved solving a number of particular problems. The first task was to develop a schematic diagram of the formation of an insulating shell. The second is the study of the thermal characteristics of the shell under operating conditions characteristic of various climatic zones.

Three groups of requirements were taken into account when developing the basic design of the insulating shell. Heat saving was assessed by the thermal resistance of the structure and the temperature distribution over the thickness of the insulation system. Comfort was 
assessed by the microclimate created in the premises, that is, by the temperature and humidity conditions. The working conditions of the structures and the weather resistance (first of all, from negative and alternating temperatures) of the load-bearing elements were the criteria for durability.

The research of the thermal characteristics of the insulating shell in particular and the structure as a whole was carried out using a special computer program "THERM" which meets the requirements of the set of rules SP 50.13330.2012 and makes it possible to study heat transfer processes. The basis of the program solutions is the modeling of twodimensional heat transfer in the enclosing building structures: walls, floor structures, foundations, also taking into account the special conditions for windows and doors. The use of the program allows evaluating the energy saving factors characteristic of the structure, and the analysis of the temperature distribution in the system allows monitoring the possibility of moisture condensation and assessing the tightness of the insulating shell. The program can estimate the factor of radiative heat transfer, taking into account mutual irradiation and shading of the calculated surfaces. Convenient program interface and the ability to use graphical options makes the program intuitive and easy to use.

\section{Results}

The classical system of insulating structures on pile foundations (Fig.1a) includes two main components: the wall as a plastering system with insulation (analogue is the Facade's thermoinsulation composite systems - FTCS), and the floor structures (above the ventilated room) is insulated with several layers of heat-insulating material, laid in a checkerboard pattern. Such a solution presupposes the presence of a permanent cold air infiltration bridge (shown in Fig. 1a (V)) along the joints of structural elements and heat transfer bridges through uninsulated structural elements. The joint of structural elements is not only an area of active infiltration of cold air, but also by conductive heat transfer due to unqualified laying insulating board and their loose connection to structures. The experience of operating buildings insulated with such a system indicates both high heat losses and inconvenient conditions in the premises of the first floor.

At insignificant negative temperatures of the outside air or at transitions through $0^{\circ} \mathrm{C}$, (is typical for temperate climatic zones and in the off-season), the load-bearing structures of the building are in the area of alternating temperatures. This is undesirable both from the point of view of frost resistance of the structure, and from the point of view of moisture accumulation both in the load-bearing structures and in the heat-insulating layers due to the transition of temperature through the dew point temperature. An increase in the moisture content of the insulating layers, first of all, increases their thermal conductivity and reduces thermal resistance. In addition to destructive processes in the material, it leads to the appearance of fungus and mold.

The concept of developing an insulation system for the building structure on pile foundations included the following positions. Firstly, this is the provision of the thermal resistance required for the climatic region along the wall surface. Secondly, this is the exclusion of possible ways of cold air infiltration and conductive heat transfer outside the insulating shell.

The result is the insulation system shown in fig. 1b. This solution involves insulation with weather-resistant heat-insulating roll material along the outer surface of the floor structure, laying several layers of heat-insulating plates along the floor structure and installing additional insulation according to the "floating floor" principle. After the structure was formed in a general form, the question arose about the choice of materials for this structure 
Particular attention was paid to the material located along the outer perimeter of the floor structure above the ventilated space. The requirements for the material were very responsible: it had to have low thermal conductivity, vapor permeability and water absorption, high weather resistance and had to maintain its properties in a wide temperature range from -60 to $+60^{\circ} \mathrm{C}$. Foamed uncrosslinked polyethylene (FPE), or rather rolled products based on it, with a metallized coating, corresponded to these properties. Rolled foamed polyethylene with or without a metallized coating is widely used in insulation systems for residential and industrial facilities, logistics centers and warehouses and so on [12-14]. Particularly attractive is the TEPOFOL technology, which ensures the formation of a seamless connection of individual rolls due to their welding along on the lock connection.

Products made of extruded foamed polystyrene (XPS-boards) or foamed polyisocyanurate (PIR-boards) can be used as thermal insulation boards. These materials have low thermal conductivity and water absorption and have stable properties in fairly wide ranges of temperatures and humidity. Rolled foamed polyethylene is also used as insulation for the "floating floor".
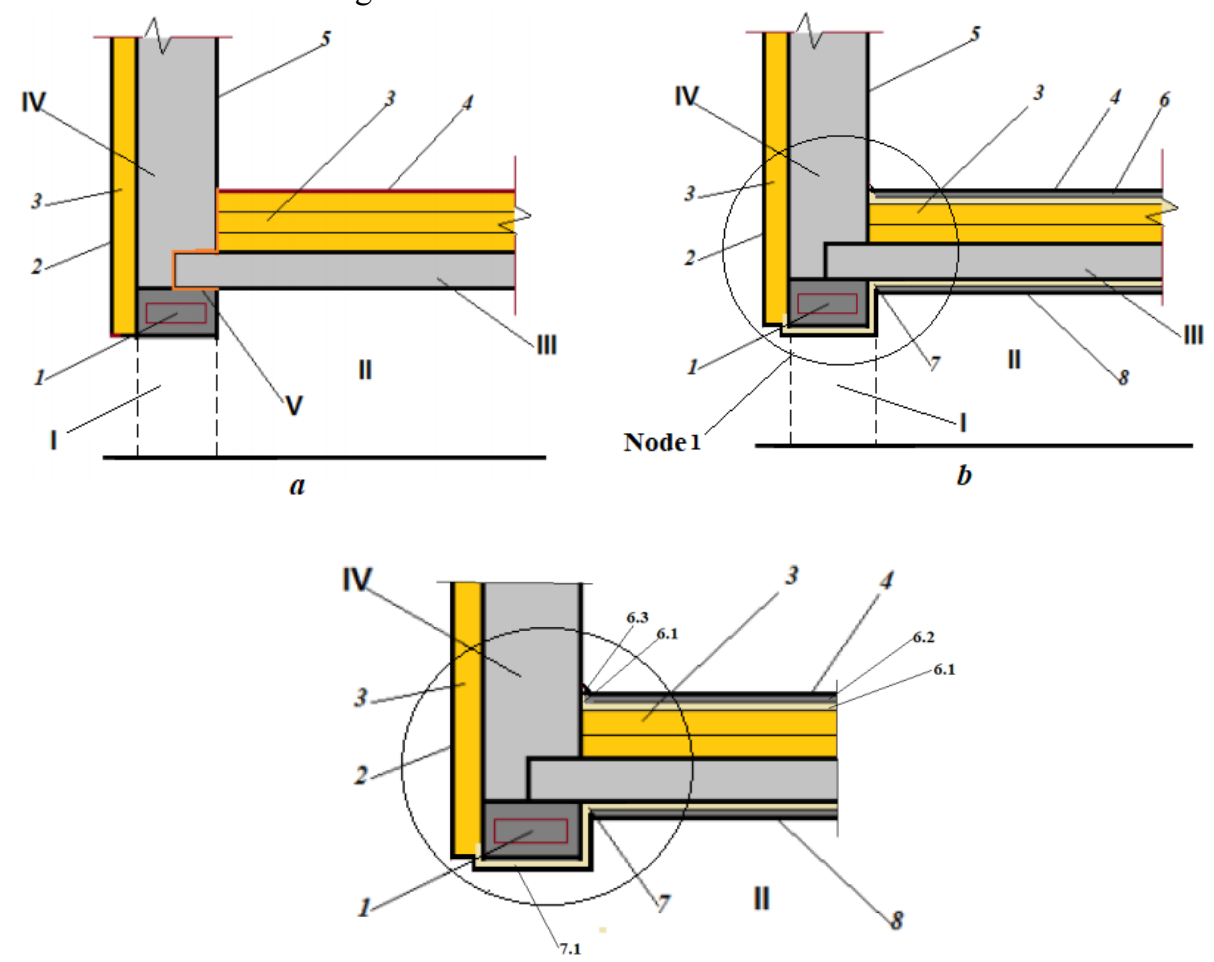

Fig.1. The floor structure of residential building (the section - wall between columns and detailing of node 1): $a$ - without insulation of the floor structure over the ventilated space; $b$ - with insulation of the floor structure over the ventilated space; I - column; II - ventilated space; III- the floor structure over the ventilated space; IV - bearing wall; V - area of increased heat transfer and cold air infiltration; 1 -binding of columns; 2 - facade insulation system; 3 -XPS thermal insulation board; 4 - top coat of floor; 5 - interior wall cladding; 6 - floating floor system (dry build), includes: 6.1 FPE layer $20 \mathrm{~mm}$ thick, installed on the wall; 6.2 - chrysotile cement sheet $10 \mathrm{~mm}$ thick (or fibercement sheet), then the top coat of floor; 6.3 - floor moulding; 7 - insulation above the ventilated space; 7.1 - insulation before FTCS (completely blocks the infiltration flow at the junction); 8 protective lining. 
The insulating cladding of the walls is made according to the technology of insulated plaster facades (FTCS), and the ceiling over the ventilated space is insulated with several layers of XPS-plates, laid with offset joints. Insulation made of rolled foamed polyethylene is mounted along the entire base (under the overlap) and installed on the wall up to the basement part of the FTCS. Thus, rolled foamed polyethylene with a metallized coating completely blocks the infiltration flow at the junction of the wall ceiling. Separate rolls of foamed polyethylene are mounted in the lock, followed by welding the joint with hot air using a construction dryer. Considering that foamed polyethylene has not only low thermal conductivity, but also very low vapor, moisture and wind permeability, we can say that a seamless insulating shell is formed.

The implementation of computer calculations was aimed at assessing the distribution of temperature fields and thermal resistance of insulation systems operating in different temperature conditions. The calculations used the following input data. The strapping of the columns was carried out with reinforced concrete grillage (average density $-2400 \mathrm{~kg} / \mathrm{m}^{3}$, thickness $-200 \mathrm{~mm}$, thermal conductivity in operating conditions $\left.\mathrm{B}\left(\lambda_{\mathrm{B}}\right)-1.86 \mathrm{~W} /\left(\mathrm{m}^{\circ} \mathrm{C}\right)\right)$. Facade's thermoinsulation composite systems (FTCS) along the surface of the walls: mineral wool slabs with an average density of $80 \mathrm{~kg} / \mathrm{m}^{3}$, thickness of $100 \mathrm{~mm}$, thermal conductivity $\left.\lambda_{\mathrm{B}}-0.46 \mathrm{~W} /\left(\mathrm{m}^{\circ} \mathrm{C}\right)\right)$. The basement part is made of extruded foamed polystyrene (XPS-plates) $100 \mathrm{~mm}$ in thick at a height of $1 \mathrm{~m}$ from the bottom edge of the wall above the ventilated space. XPS-boards with an average density of $30 \mathrm{~kg} / \mathrm{m}^{3}$, with a thickness of $50 \mathrm{~mm}$ each layer, thermal conductivity $\lambda_{\mathrm{B}}-0.031 \mathrm{~W} /\left(\mathrm{m}^{\circ} \mathrm{C}\right)$. The insulation over the ventilated space was made of rolled foamed polyethylene with a metallized coating $20 \mathrm{~mm}$ in thick, with an average density of $30 \mathrm{~kg} / \mathrm{m}^{3}$, thermal conductivity $\lambda_{\mathrm{B}}-0.032$ $\mathrm{W} /\left(\mathrm{m}^{\circ} \mathrm{C}\right)$. On top of the overlap, two layers of XPS-plates were laid (in a spaced manner with displaced joints) and a layer of rolled foamed polyethylene, which was put of the wall $(100 \mathrm{~mm})$ with mechanical fastening and welded into a seamless insulating shell.

With the help of the THERM computer program, the conditions of two-dimensional heat transfer in the enclosing structures of a pile building were simulated. The construction of such buildings is practiced on problem soils. Structures were taken as the basis for the calculation, the nodes of which are shown in Fig. 2 and 3.

The resulting models were analyzed in terms of the thermophysical characteristics of the structures. As a result, the optimal version of the insulation system was chosen, which is effective both in the climatic conditions of the middle zone and in the especially cold conditions of Yakutia and the Arctic.

\section{Discussion}

Modeling shows that in the places where the structure rests on the column, in view of the high thermal conductivity of the supporting structures, a "temperature bridge" is preserved, passing through the contact points of structural elements (column - strapping - load-bearing wall). At the same time, the placement of rolled foamed polyethylene on the outer insulated surface (above the cold space under the structure) and as an element of the floating floor inside the room, allows you to completely block possible paths of heat loss both due to the "temperature bridge" and due to the blocking of direct infiltration of cold air along joints of structures (Fig. 2).

The effect of a higher level is manifested in the area between the columns, where the use of combined insulation (panel extrusion foamed polystyrene (XPS) or foamed polyisocyanurate (PIR) with a contour protection from rolled foamed polyethylene) allows a completely seamless insulation shell to be formed (Fig. 3). 
Thus, the proposed design solutions based on the use of a combined insulation system make it possible to form an insulating shell that meets the requirements of both heat conservation and energy efficiency.

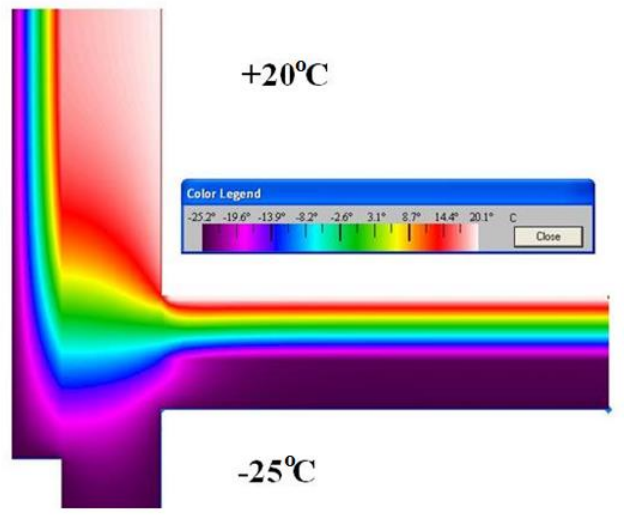

$\mathrm{a}$

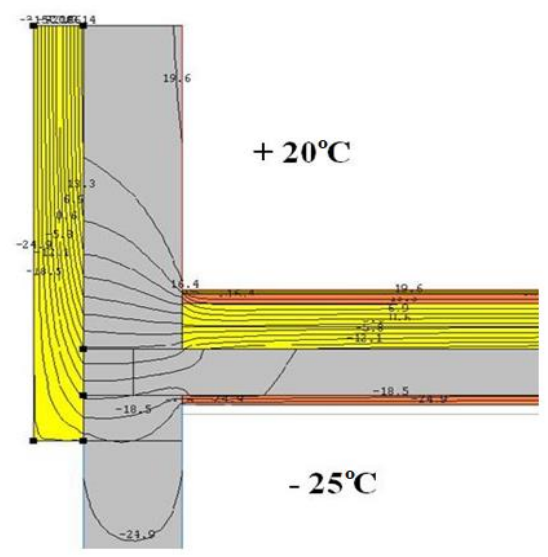

b

Fig. 2. The structure of the formation of the temperature field in a structure partially insulated above the ventilated space: a - visualization of the temperature field; b - graphic interpretation of the temperature distribution (Moscow region).

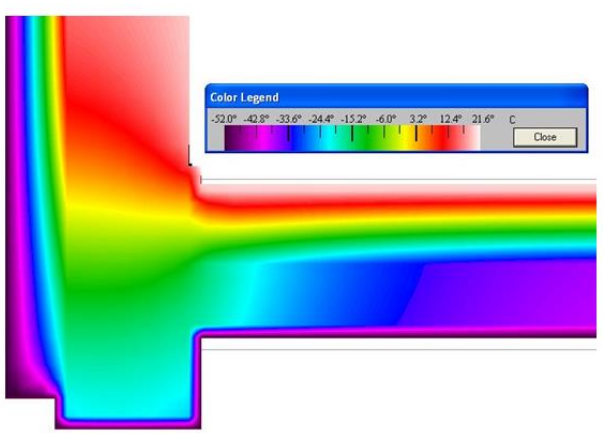

a

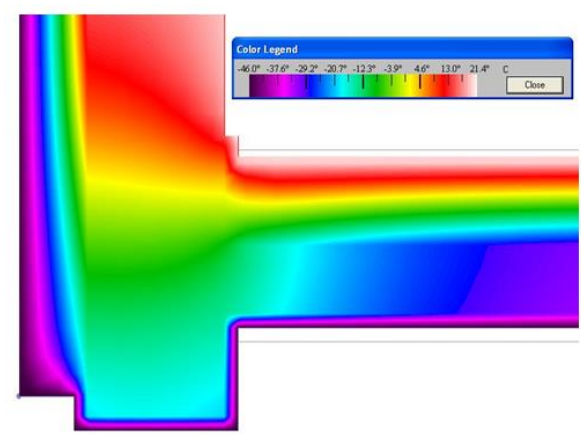

b

Fig. 3. The structure of the formation of the temperature field in the structure isolated above the ventilated space (between the support columns): a - visualization of the temperature field for Yakutsk (temperature - minus $52^{\circ} \mathrm{C}$ ); $\mathrm{b}$ - visualization of the temperature field for Norilsk (temperature minus $\left.46^{\circ} \mathrm{C}\right)$.

The effect of using this system solution increases if structures operating in conditions of significant negative temperatures are insulated (Fig. 3). It should be noted that the studies carried out at the NRU MSCU [15-17] showed that all insulating materials used can operate at temperatures up to minus $80^{\circ} \mathrm{C}$ without loss of properties and thermal insulation ability. With a thickness of XPS-thermal insulation of $200 \mathrm{~mm}$ and a thickness of FPEinsulating coating of $20 \mathrm{~mm}$, the thermal resistance of the insulating shell is not less than $4.0 \mathrm{~m}^{2 \circ} \mathrm{C} / \mathrm{W}$, and the calculated one is not less than $6.0 \mathrm{~m}^{2 \circ} \mathrm{C} / \mathrm{W}$.

The operating conditions of thermal insulation based on extruded polystyrene foam, polyisocyanurate foam and polyethylene foam are quite consistent with the studied ranges of operation of these materials and their operational resistance, which assumes the possibility of long-term operation of the insulation system. The developed insulation systems for building structures allow achieving the standard thermal resistance, minimizing possible heat transfer bridges. 


\section{Conclusion}

The operating conditions of thermal insulation based on extruded foamed polystyrene, foamed polyisocyanurate and foamed polyethylene are quite consistent with the studied ranges of operation of these materials and their operational resistance, which assumes the possibility of long-term operation of the insulation system. Rolled foamed polyethylene with a metallized coating forms a seamless insulating shell, completely blocks the possible paths of cold air infiltration at the joints of the structural elements, thereby reducing possible heat losses. Calculation of temperature fields using the THERM computer program showed that the developed insulation systems for building structures allow achieving the standard thermal resistance, minimizing possible heat transfer bridges. With a thickness of XPS-thermal insulation of $200 \mathrm{~mm}$ and a thickness of FPE-insulating coating of $20 \mathrm{~mm}$, the thermal resistance of the insulating shell is not less than $4.0 \mathrm{~m}^{2}{ }^{\circ} \mathrm{C} / \mathrm{W}$.

\section{References}

1. A.D. Zhukov, K.A. Ter-Zakaryan, D.U. Tuchaev, E.S. Petrovsky, International Agricultural Journal, 1 (361), 65-67 (2018)

2. E.A. Zinovieva, A.D. Zhukov, A.K. Ter-Zakaryan, I.V. Bessonov, Housing, 7, 35-40 (2019)

3. A. D. Zhukov, K.A. Ter-Zakaryan, V.S. Semenov, S.D. Kozlov, E.A. Zinovieva, E.D. Fomina, MATEC Web Conf., 251, 01014 (2018)

4. A.D. Zhukov, K.A. Ter-Zakaryan, V.S. Semenov, IFAC PaperOnLine, 51/30, 803-807 (2018).

5. R.S. Fedyuk, A.V. Mochalov, V.A. Simonov, Bulletin of the Engineering School of the FEFU, 2 (11), 39-44 (2012)

6. N.P. Umnyakova, V.M. Tsygankov, V.A. Kuzmin, Zhilishchnoe Stroitel'stvo, 1-2, 3842 (2018)

7. I.Ya. Gnip, V.I. Kerchulis, S.Y. Vaitkus, Stroitel'nye materialy, 12, 40-44 (2012)

8. N.P. Umnyakova, I.V. Bessonov, A.D. Zhukov, E.A. Zinoveva, MATEC Web Conf., 298, 00013 (2019)

9. P. Gudkov, P. Kagan, A. Pilipenko, E.Yu. Zhukova, E.A. Zinovieva, N.A. Ushakov, E3S Web Conf., 97, 01039 (2019)

10. P.M. Zhuk, A.D. Zhukov, Ecology and industry of Russia, 4, 52-57 (2018)

11. A.D. Zhukov, K.A. Ter-Zakaryan, I.V. Bessonov, V.S. Semenov, A.V. Starostin, Building materials, 9, 58-61 (2018)

12. A.D. Zhukov, K.A. Ter-Zakaryan, I.V. Bessonov, V.A. Lobanov, A.V. Starostin, Building Materials, 6, 49-55 (2019)

13. S. Kozlov, B. Efimov, E. Bobrova, E. Zinovieva, E. Zhukova, E3S Web Conf., 97, 06010 (2019)

14. V.S. Semenov, I.V. Bessonov, K.A. Ter-Zakaryan, A.D. Zhukov, E.A. Mednikova, Problemele energeticii regionale, 4 (48), 101-111 (2020)

15. A. Zhukov, T. Dovydenko, S. Kozlov, K. Ter-Zakaryan, E. Bobrova, E3S Web Conf., 91, 02032 (2019)

16. A.D. Zhukov, K.A. Ter-Zakaryan, E.Yu. Bobrova, Moscow Economic Journal, 5-3, 92-104 (2018)

17. E. Bobrova, A. Pilipenko, A. Zhukov, E3S Web of Conf., 91, 02019 (2019) 